\title{
Circular Business Models: Defining a Concept and Framing an Emerging Research Field
}

\author{
Julia L. K. Nußholz \\ International Institute for Industrial Environmental Economics (IIIEE), Lund University, Tegnérsplatsen 4, \\ 22350 Lund, Sweden; julia.nussholz@iiiee.lu.se; Tel.: +46-46-222-0228
}

Received: 22 August 2017; Accepted: 28 September 2017; Published: 10 October 2017

\begin{abstract}
To aid companies in transitioning towards a circular economy and adopting strategies such as reuse, repair, and remanufacturing, the concept of circular business models has been developed. Although the concept draws on contributions from various academic disciplines, and despite its increasingly frequent use, few scholars clearly define what a circular business model is. Understanding about what makes a business model circular is diverse, hampering the theoretical development and practical application of circular business models. This study aims to help frame the field of circular business model research, by clarifying the fundamentals of the concept from the perspectives of resource efficiency and business model innovation. Expanding on these findings, a review of how the concept is used in recent academic literature is provided. It shows that a coherent view is lacking on which resource efficiency strategies classify a business model as circular. This study clarifies which resource efficiency strategies can be deemed as relevant key strategies for circular business models, and suggests a new definition of the concept. With the definition grounded in analysis of the fundamentals in terms of resource efficiency and business models, the study contributes to theoretical advancement and effective implementation of circular business models.
\end{abstract}

Keywords: circular economy; circular business models; business model innovation; resource efficiency; product life extension; product life cycle

\section{Introduction}

To improve resource productivity and efficiency of our society, the concept of a circular economy has recently been revived [1,2]. The circular economy is a paradigm that suggests a redesign of the current linear economic system, largely based on linear resource flows, towards closed-loop resource flows that can preserve the embedded environmental and economic value in products over time [3-5]. The circular economy has the potential to lead to increased resource efficiency and generate environmental gains through reduced raw material extraction and waste generation $[3,6]$.

To help companies operate economically in a circular economy, the concept of a circular business model has been developed [2,7,8]. Circular business models generally reconcile creation of commercial value with adoption of resource efficiency strategies, such as repair and remanufacturing, by capitalising on the economic and environmental value embedded in products [8,9]. In contrast to linear business models, in which a product is commonly downgraded after a single use phase and its embedded value is lost, circular business models support the development of product systems that incorporate strategies to preserve the embedded value at the highest possible level of utility [10].

In recent years, circular business models have received attention from practitioners [11-13], policy makers [1] and researchers [7,8,14-17]. However, despite the increasing use, few scholars provide a clear definition of circular business models, and no common understanding of the concept has been established. To date, many fundamental questions in the emerging field remain unanswered. For instance, which elements, features, or contributions to changing resource flows make a business model circular, and how can it be distinguished from a linear business model [18]? 
These inconsistencies may partly stem from the fact that, although the term is relatively new, it builds upon two well-established notions: (1) business models from the management field; and (2) circular strategies from the resource efficiency field. While business models are used to analyse the value creation architectures of businesses [19], circular strategies stem from a research field that studies resource efficiency through circular resource flows to preserve the embedded environmental and economic value [20]. However, the integration of these perspectives has yet to be fully developed to aid effective implementation of circular business models and to secure their potential resource efficiency gains.

This study aims to help frame the field of circular business models by clarifying the fundamentals of the concept from the perspectives of resource efficiency and business model innovation, and exploring how these two perspectives are linked. The study also aims to systematise current knowledge regarding the circular business model concept, including the main considerations behind securing the potential resource efficiency gains when implementing circular strategies. Through this three-fold analysis, a definition of the circular business model concept is proposed.

The article is structured as follows. Firstly, the research design and the methodology is presented. This is followed by a literature analysis (Sections 3-5), including an overview of the fundamentals of the circular business model concept (Section 3), how it is currently used (Section 4), and the main contingencies that can impede resource efficiency gains from circular strategies (Section 5). The findings of this analysis are highlighted and a revised definition of the concept is offered (Section 6). The final section (Section 7) includes the discussion and final remarks.

\section{Research Design and Methodology}

This study first provides a background on related research fields, i.e., business models from the management field and circular strategies from the resource efficiency field (Section 3). To analyse the current use of the circular business model concept (Section 4) and position it in relation to related fields, recent academic literature on circular business models is reviewed and systematised. A systematic literature review was conducted as described by Jesson et al. [21].

The scope of the search was limited to academic studies that explicitly referred to the concept of circular business model. For example, studies that aim to conceptualise the term "circular business model" [15] or to examine companies' transition towards a circular business model [17] were considered relevant. Studies that address business models for sustainable development, product service systems (PSSs) or industrial symbiosis without an explicit reference to advancing circular economy were excluded from the analysis. Search terms used were "circular business model", "business models for circular economy", "business models for remanufacturing", and "closed-loop business models". Other search terms, such as "closed-loop manufacturing" or "circular business case" were omitted to keep the scope manageable.

The search was conducted via the Scopus database, as it is the largest database for academic work and provides access to a wide variety of journals (e.g., Journal of Industrial Ecology, Journal of Cleaner Production, Business Strategy and the Environment, Journal of Remanufacturing, Sustainability, Resources, and International Journal of Waste and Resources) and conference proceedings in the field (e.g., Ecodesign Symposium and Industrial Product-Service-Systems). No timeframe was applied (as of October 2016). The search using the selected key words resulted in 302 articles and conference proceedings. After checking the titles to ensure the relevance to the research inquiry, the abstracts were checked and, if considered appropriate, the full paper was analysed. The resulting set of studies was expanded through cross-reference techniques in several individual articles to provide sufficient background information on specific research results, concepts or terms referred to in the included literature. After filtering, 44 documents were considered relevant to analysing the current use and understanding of the concept.

By focusing on studies that explicitly use the term "circular business models", studies that investigated various circular business model elements that do not use the term may have been 
overlooked. Similarly, a large body of knowledge may be found in other research streams on reverse logistics and closed-loop production, but incorporating these fields and additional search terms would have exceeded the scope of this study. Nevertheless, the author believes that the applied search terms and exclusion criteria were appropriate to realise the aim of this study and capture the current understanding of circular business models in academic discourse.

\section{Fundamentals of Circular Business Models}

This section is concerned with clarifying the fundamentals of the circular business model concept. Existing knowledge on resource efficiency and circular strategies (Section 3.1) and on the business model concept (Section 3.2) is reviewed. This is followed by exploration of how these are linked, i.e., how business model innovation can aid the implementation of circular strategies (Section 3.3).

\subsection{Resource Efficiency and Circular Strategies}

Many research streams have contributed to developing the principles, strategies, and implementation approaches that underlie the circular economy concept. These include the fields of Industrial Ecology [4,20,22], Product-Service Systems [23-26], Ecodesign [27,28], and Design Engineering for Functional Sales [29-32]. Generally, scholars in these fields have developed and studied a wide range of strategies for changing material flows to improve resource efficiency and value preservation. These strategies can be employed at various stages of the product life cycle, such as at the production and use phases [6]. Three major frameworks exist that categorise the existing range of resource efficiency strategies $[6,8,33]$ (Figure 1). While the frameworks of Willskytt et al. [33] and Bocken et al. [8] focus specifically on resource efficiency in a circular economy context, Allwood et al. [6] is concerned with material efficiency in general. Figure 1 provides an overview of resource efficiency strategies and their categorisation in each of the frameworks, and the relevant life cycle stages at which they come into effect (at the bottom of Figure 1).

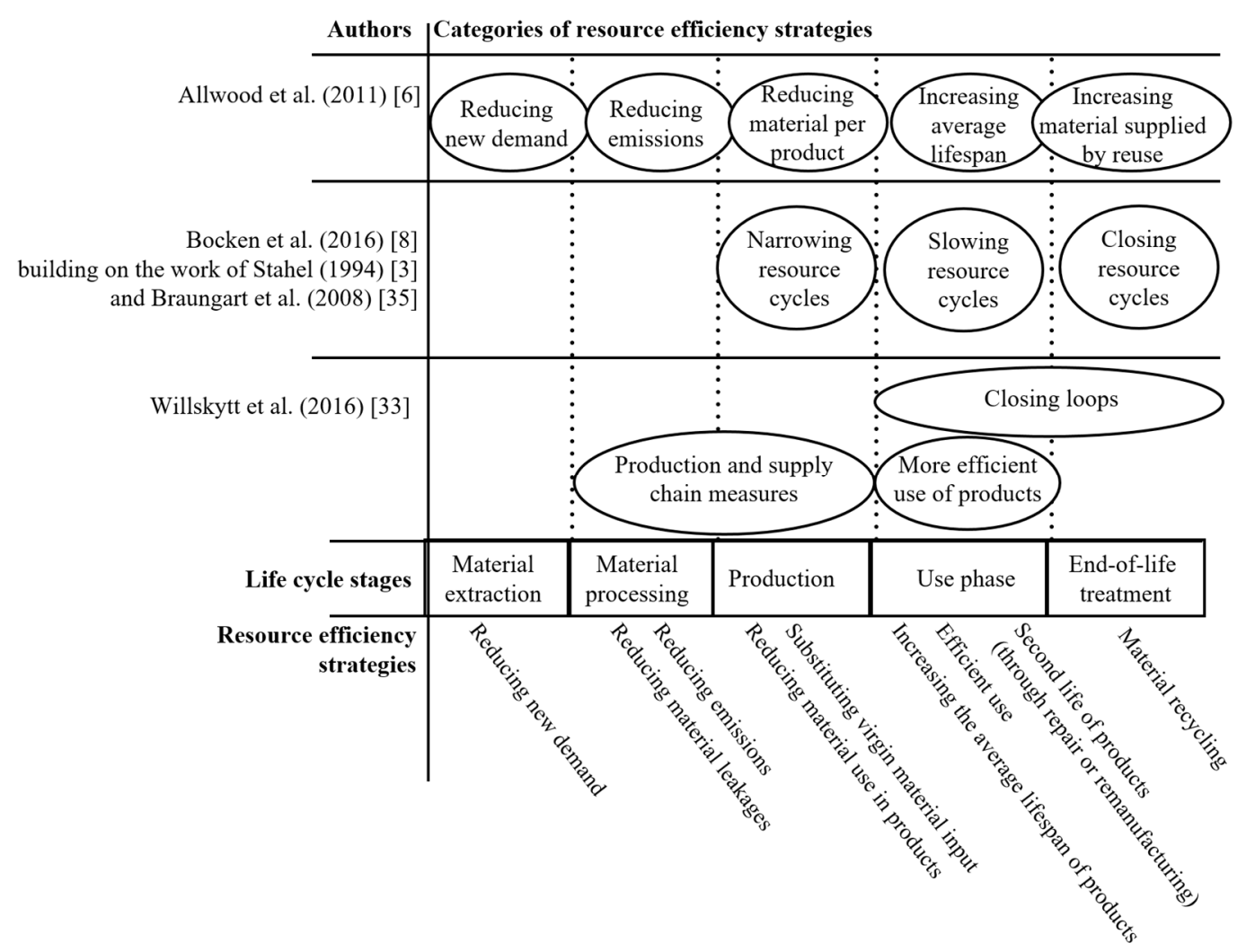

Figure 1. Overview of existing categorisations of resource efficiency strategies. 
As Figure 1 shows, strategies for cycling products, parts, or materials (from here onwards referred to as circular strategies) have been developed to improve resource efficiency in the use and end-of-life phases. This set of circular strategies includes enabling a second life for products and parts through repair or remanufacturing and enabling material recycling when the end-of-life is irreversibly reached (Figure 1). By reintegrating the recovered secondary products, parts, and materials (from here onwards referred to as secondary production [34]) in the value chain, this set of circular strategies also addresses impacts occurring at the beginning of any product life cycle, as they can substitute resource-intensive primary production [34]. See Section 5 for a discussion of this.

Most of these circular strategies can also be understood as measures to extend the useful life of resources. This partly explains the observation that scholars classify this set of circular strategies differently and use different terminologies (Figure 1). For instance, 'more efficient use of product' and 'closing loops' in Willskytt et al. [33] correspond somewhat to 'slowing resource cycles and closing resource cycles' in Bocken et al. [8]. Another difference is that, even if the same terminology is used, e.g., 'closing loops', the defining boundaries underlying the classifications can be different. For instance, for Bocken et al. [8] 'closing the loop' only involves material recycling, while for Willskytt et al. [33] enabling a second life for products and parts is also part of 'closing the loop' if products and parts are reused by a new user, as opposed to reuse by the same user, which is regarded as a way to extend product life.

While all existing strategies are relevant, the set of circular strategies shown above is thought to contribute to a more systemic and radical change compared with strategies that achieve incremental resource efficiency improvements [2,8]. This is because circular strategies can contribute to closed resource loops that can maintain quality and productivity over time, thereby reducing the speed of the flow of products and materials through the economy $[3,8,35]$. However, despite the potential of circular strategies to contribute to a more systemic change, it should be noted that they do not have the greatest potential for resource efficiency gains in all circumstances. For instance, if the use phase is dominant (e.g., in terms of energy or water usage), strategies for efficient use are likely to have the greatest resource efficiency potential. In addition, strategies addressing the material processing and production phases are not considered as circular strategies, yet they may be vital to enable circular strategies at later life cycle phases of a product (e.g., selection of materials that enable recycling).

Some of the existing resource efficiency strategies (Figure 1) can be realised at company level within its own processes and product development, e.g., reduced material leakages and reduced material use in products. However, realising circular strategies often extends beyond company boundaries. Wells and Seitz [36], who identify four archetypical closed-loop value chains, show that only the 'internal loop' (material reuse within the point of manufacture) is realisable at company level. The 'post-business loop' (material exchange between distinct companies) requires coordination and alignment of business models between at least two companies. The 'post-consumer loop' (return from consumers back to the manufacturer via a company-based collection scheme) and 'post-society loop' (return from consumers via an independent network to a different point of manufacture) are often managed by entirely separate businesses and logistic systems [36].

While many of the resource efficiency strategies require only marginal changes in companies' processes and value chains, implementing circular strategies often requires more holistic and radical changes beyond the boundary of a company. To realise these changes and capitalise on circular strategies, the idea of business model innovation has recently gained prominence [18]. Section 3.2 explores the conceptual understanding of business models, followed by an examination of how business model innovation can serve as an enabler of circular strategies (Section 3.3).

\subsection{Business Model Concept}

Business models can be understood as a structured management tool [37] used to present the company's organisational structure and value creation processes [19,38]. Teece [39] describes a business model as the organisational and financial architecture, defining how an organisation converts 
resources and capabilities into economic value. A definition widely cited is the one of Osterwalder and Pigneur [40], stating that a business model is the core logic how a company creates, delivers, and captures value (Table 1 ).

Table 1. Core activities in a business model, adapted from Osterwalder and Pigneur [40] and Richardson [38].

\begin{tabular}{ll}
\hline Value Dimension & Corresponding Question \\
\hline Value proposition & What value is provided and to whom? \\
Value creation and delivery & How is value provided? \\
Value capture & How does the company make profit and capture other forms of value? \\
\hline
\end{tabular}

A framework for conceptualising business models that has been acknowledged for its practical relevance is the "business model canvas" by Osterwalder and Pigneur [40,41]. The authors distinguish between nine business model elements: key resources, key partners, customer segments, customer relationships, channels, value proposition, revenue streams, cost structure, and key activities (Figure 2).

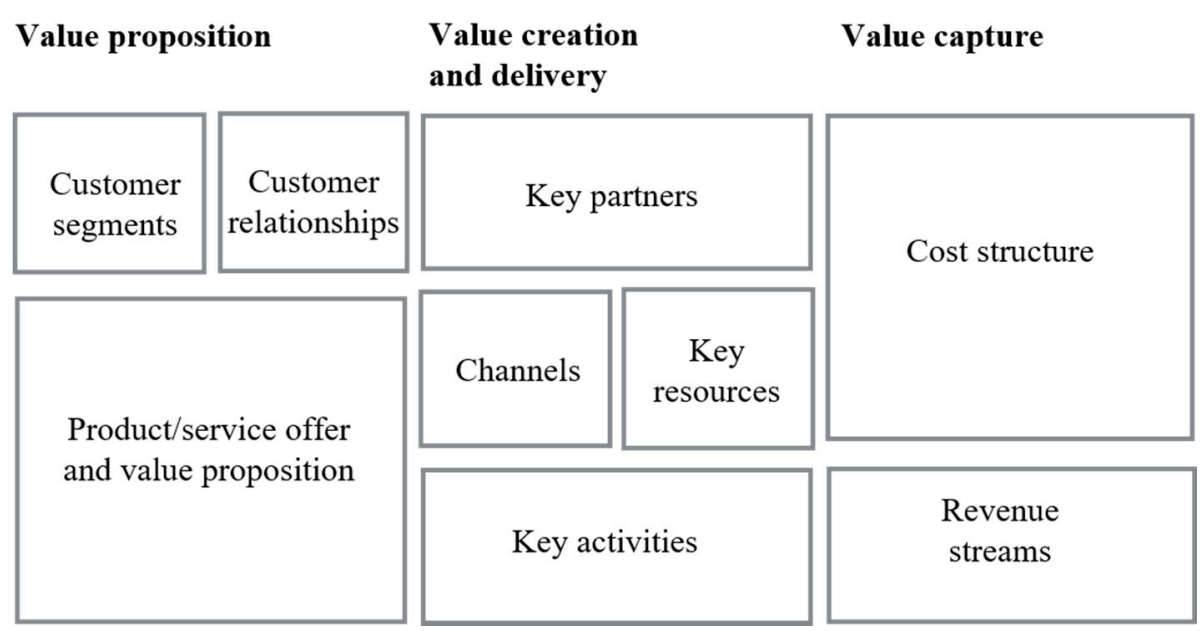

Figure 2. Business model conceptualisation, adapted from Osterwalder and Pigneur $[40,41]$.

Innovating the business model has been the focus of research, as merely innovating technologies, products and processes has proved insufficient to secure a competitive advantage [42]. Business model innovation can play two roles. Firstly, as a vehicle to innovation, it allows managers to bring innovative products and technologies to the market. Secondly, as a source of innovation itself, it can change "the old way of doing things", and goes beyond traditional innovation dimensions such as product, process, and organisation [43].

Innovating business models comprises a reconfiguration in the business model elements, including innovating: (1) the content (adding new activities); (2) the structure (linkages and sequencing of activities); or (3) the governance (the control/responsibility over an activity) of the activity system between the company and its network [44]. Business model innovation can alter how an organisation is connected to external stakeholders, and how it engages in economic exchanges with them to create value for all partners [45,46]. As such, it can help coordinate technological and organisational innovations that involve a wider set of stakeholders within a value network [47]. The following section explores in more detail why business model innovation can be an important enabler for circular strategies, and how it can aid their implementation.

\subsection{Business Model Innovation as Enabler of Circular Strategies}

Currently, most business models are designed and optimised to fit the linear system, in which negative externalities in the environment are not included in resource prices. Implementing circular 
strategies requires rethinking of the value creation logic to ensure that they bring about economic benefits. By rethinking the three value dimensions, i.e., what value is proposed, how value is created and delivered, and how value is captured (Table 1), business model innovation provides a more systemic approach for aligning the value creation logic of the company with circular principles. As Figure 3 illustrates, a circular strategy and the associated changes in material flows can be embedded into the value creation logic to aid its implementation. Aligning the three value dimensions and adjusting the configuration of business model elements can facilitate its operation, as described below.

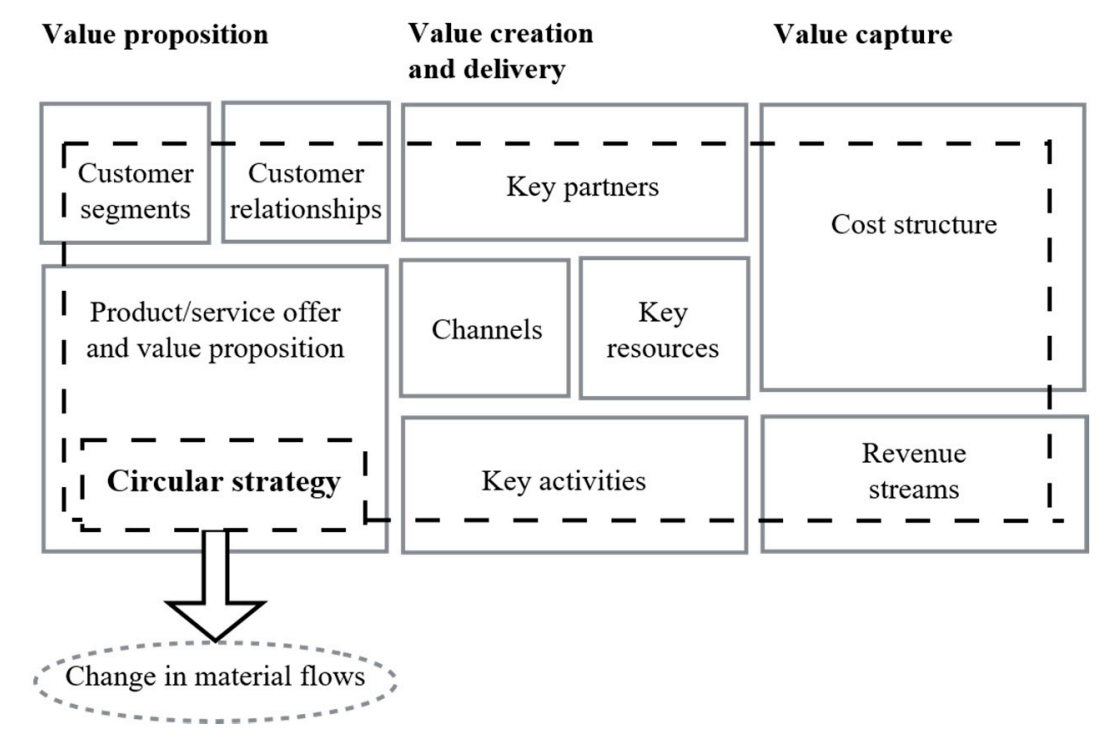

Figure 3. Illustration of embeddedness of a circular strategy in a business model.

The value proposition in a circular business model can be created to build a product/service offer that contains and deliberately uses a circular strategy to create value (Figure 3). The offer can be devised in a way that proactively addresses preservation of the economic and environmental value embedded in products, parts, and materials. Thereby, material flows associated with an offer can be altered towards increased resource efficiency and closed-loop resource flows (Figure 3). One example is a product designed to enable product life extension and value preservation through design for long-life, repair or remanufacturing [7]. Adjusting the offer from selling ownership of a product to a PSS has also been widely discussed as a mechanism to facilitate the collection of products and application of circular strategies [32,48-51]. For some types of products and customer segments, this has also been shown to create additional value to users $[9,48,50,52]$. Innovating the value proposition can help bring the offer to the market, and help identify the right customer segments, for whom the associated value is attractive [52]. Examples are customers with high environmental awareness and preference for durable products because of convenience and lower total cost of ownership [52,53]. Customer relationships can be developed, not only to create additional value for customers, but also to help remove barriers to the collection of products. For instance, Östlin et al. [31] show that realising remanufacturing requires targeting of customer segments willing to return products and establish customer relationships that support the return of products, e.g., a service-contract or a buy-back scheme.

Value creation and delivery elements of a business model can be designed to realise the potential value of offers and their embedded circular strategy. Considerations for creating the potential value and effectively delivering it include:

- the selection of the right key activities of a company (e.g., whether operating a leasing scheme [54] or another type of PSS is useful [49,50]; whether resource recovery is performed in house or outsourced [55]);

- $\quad$ acquiring the key resources (e.g., collection points for reverse logistics); 
- $\quad$ acquiring key partners (e.g., supplier of secondary material or service providers [56]); and

- $\quad$ setting up appropriate channels (e.g., motivating the return of goods).

Whalen et al. show that innovating these business model elements can address and remove barriers to creating value by extending the useful life of products [56,57], such as by establishing partnerships for securing sufficient supply of secondary products [56]. In addition, innovating these elements helps companies develop the networks required to coordinate closing material flows at value chain level. This is relevant, as many material flows can only be effectively closed within a larger value chain network (especially the post-business, post-consumer, or post-society loops as presented in Section 3.1) [36], e.g., by establishing alliances with other stakeholders, creating value for various value chain partners, or altering the way economic transactions between partners take shape [45].

The value capture elements can be devised to capitalise on additional revenue sources, cost reductions or non-monetary benefits associated with circular efficiency strategies and value preservation. Additional revenue streams can stem from capitalising on markets for secondary production capturing value from redistributing, repairing and reselling of post-consumer products [7]. Revenue streams could also include profit either from selling a long-life product at a higher price, from adopting a PSS and selling access to a product [51], or from providing maintenance services [14]. Changes in the cost structure can be realised, for example, by substituting higher-priced primary production with secondary production or avoiding costs related to end-of-life disposal [17]. In addition to direct economic gains, Schenkel et al. [58] show that multiple other indirect benefits occur in closed-loop chains, including customer, informational, and environmental value that can be captured.

Against the background of the fundamental pillars of the circular business model concept, the following section explores in more detail how the concept is understood in the current academic discourse.

\section{Current Understanding of Circular Business Models}

With the variety of possible resource efficiency strategies relevant in the context of the circular economy (Section 3.1), the term circular business model leaves ample room for interpretation. This section reviews how the concept is currently used in recent academic literature and which resource efficiency strategies authors talk about when using the term circular business model. The existing knowledge base about definition of circular business models (Section 4.1), circular business model types (Section 4.2), and potential differences from linear business models (Section 4.3) is systematised.

\subsection{How Are Circular Business Models Understood?}

Definitions are an important starting point for research as they clarify a concept's objectives and prevent concepts being used arbitrarily. Reviewing academic literature on circular business models shows that authors rarely provide a clear definition. To date, three definitions have been formulated $[17,59,60]$. The comparison in Table 2 reveals several overlaps in understanding what is meant by circular business models, but also some discrepancies. While scholars agree on established business model concepts ("the value creation logic" and the business rationale on "how an organization creates, delivers, and captures value"), a coherent view is lacking on what resource efficiency strategies and changes in material flows classify a business model as "circular". 
Table 2. Overview of existing definitions of the circular business model concept.

\begin{tabular}{|c|c|c|c|}
\hline Author(s) & Definition & $\begin{array}{l}\text { Reference to the } \\
\text { Business Model }\end{array}$ & $\begin{array}{l}\text { Resource Efficiency } \\
\text { Strategies or Changes } \\
\text { in Resource Flows } \\
\text { Considered }\end{array}$ \\
\hline Roos (2014) [59], (p. 257) & $\begin{array}{l}\text { "A circular value chain business model } \\
\text { (or green business model) is one in } \\
\text { which all intermediary outputs that } \\
\text { have no further use in the value } \\
\text { creating activities of the firms are } \\
\text { monetised in the form of either cost } \\
\text { reductions or revenue streams." }\end{array}$ & $\begin{array}{l}\text { - Value creating activities } \\
\text { of the firm } \\
\text { Monetisation in form of } \\
\text { cost reductions or } \\
\text { revenue streams }\end{array}$ & $\begin{array}{l}\text { Utilising intermediary } \\
\text { outputs that have no } \\
\text { further use in value } \\
\text { creating activities }\end{array}$ \\
\hline $\begin{array}{l}\text { Linder and Williander } \\
\text { (2015) [17], (pp. 2-3) }\end{array}$ & $\begin{array}{l}\text { "[... ] a business model in which the } \\
\text { conceptual logic for value creation is } \\
\text { based on utilising the economic value } \\
\text { retained in products after use in the } \\
\text { production of a new offerings. Thus, } \\
\text { a circular business model implies a } \\
\text { return flow to the producer from users, } \\
\text { though there can be intermediaries } \\
\text { between the two parties [ ... and] } \\
\text { always involves recycling, } \\
\text { remanufacturing, reuse or of their } \\
\text { sibling activities (e.g., refurbishment, } \\
\text { renovation, repair)." }\end{array}$ & $\begin{array}{l}\text { - Conceptual logic for } \\
\text { value creation } \\
\text { - Utilising economic } \\
\text { value retained } \\
\text { in products }\end{array}$ & $\begin{array}{l}\text { Return flows are } \\
\text { established and } \\
\text { strategies of recycling, } \\
\text { remanufacturing, reuse } \\
\text { (including refurbishment, } \\
\text { renovation, repair) } \\
\text { implemented }\end{array}$ \\
\hline $\begin{array}{l}\text { Den Hollander and } \\
\text { Bakker (2016) [60], (p. 2) }\end{array}$ & $\begin{array}{l}\text { "A circular business model describes } \\
\text { how an organization creates, delivers, } \\
\text { and captures value in a circular } \\
\text { economic system, whereby the business } \\
\text { rationale needs to be designed in such a } \\
\text { way that it prevents, postpones or } \\
\text { reverses obsolescence, minimizes } \\
\text { leakage and favours the use of } \\
\text { 'presources' over the use of resources in } \\
\text { the process of creating, delivering and } \\
\text { capturing value." }\end{array}$ & $\begin{array}{l}\text { - Designing the } \\
\text { business rationale } \\
\text { Part of the process how } \\
\text { the organisation } \\
\text { creates, delivers, and } \\
\text { captures value }\end{array}$ & $\begin{array}{l}\text { Prevent, postpone or } \\
\text { reverse obsolescence, } \\
\text { minimise leakages and } \\
\text { favour the use of } \\
\text { "presources" }\end{array}$ \\
\hline
\end{tabular}

Existing definitions are often developed for a specific purpose of the scholars' study. The existing definitions do not clarify if it is sufficient to operate one of the included resource efficiency strategies, even if this does not guarantee that material loops are closed when the end-of-life is irreversibly reached. It also remains unclear whether a resource efficiency strategy that does not entail cycling of products, parts, or materials (e.g., developing recyclable material), but that may help to close a loop at value chain level, is also part of circular business models. This is relevant, as closing resource loops can often only be achieved at value chain level (Section 3.3). To explore the current understanding of circular business models in more detail, the following section will review the suggested typologies of circular business models.

\subsection{Which Types of Circular Business Models Are Discussed?}

Business models that capitalise on circular strategies are diverse in practice. Understanding this diversity is important for identifying their key characteristics and features. Three attempts to categorise generic types of circular business models have been made in academic literature $[7,8,14]$. These typologies are designed for different purposes. Bakker and co-workers' typology is useful to guide business model innovation at a product level [7]; Bocken and co-workers' typology presents business model innovation for specific changes in resource flows [8]; and Moreno and co-workers' typology supports studying interventions from a value chain perspective [14]. Each of the typologies distinguishes 5-6 types of circular business models that, in distinct ways, create, deliver and capture value from embedding circular strategies in their offer. Circular business model types can be understood as generic configurations of business model elements that have potential to aid application of a circular strategy, while also capitalising on the associated value flows, e.g., by adding environmental, customer and economic value [58]. 
An example of a business model type identified in all three typologies is the model exploiting the residual value in unused products by using repair strategies, e.g., the Gap-Exploiter model of Bakker et al. [7]. Another business model presented in all three typologies extends the useful lifetime of products by using remanufacturing, aided by retained ownership from adopting different types of PSS, e.g., the Access Model in both Bakker et al. [7] and Bocken et al. [8]. It is important to note that circular business model types and their suggested configurations of business model elements are not equal to more resource efficient practices or closed resource loops. They can be understood as generic business model configurations that offer mechanisms, such as capitalising on product aftermarkets (e.g., the Gap-Exploiter Model), retaining ownership (e.g., the Access Model), or enabling shared use (e.g., Sharing Platforms) that can facilitate implementing a circular strategy and capitalising on its associated value.

Figure 4 maps the various circular business model types against the resource efficiency strategies that they can facilitate (using the summary developed in Section 3.1). This shows that authors consider a large array of resource efficiency strategies in conceptualising circular business models. Strategies that go beyond the set of circular strategies (compare Section 3.1) are also considered (e.g., encourage sufficiency).

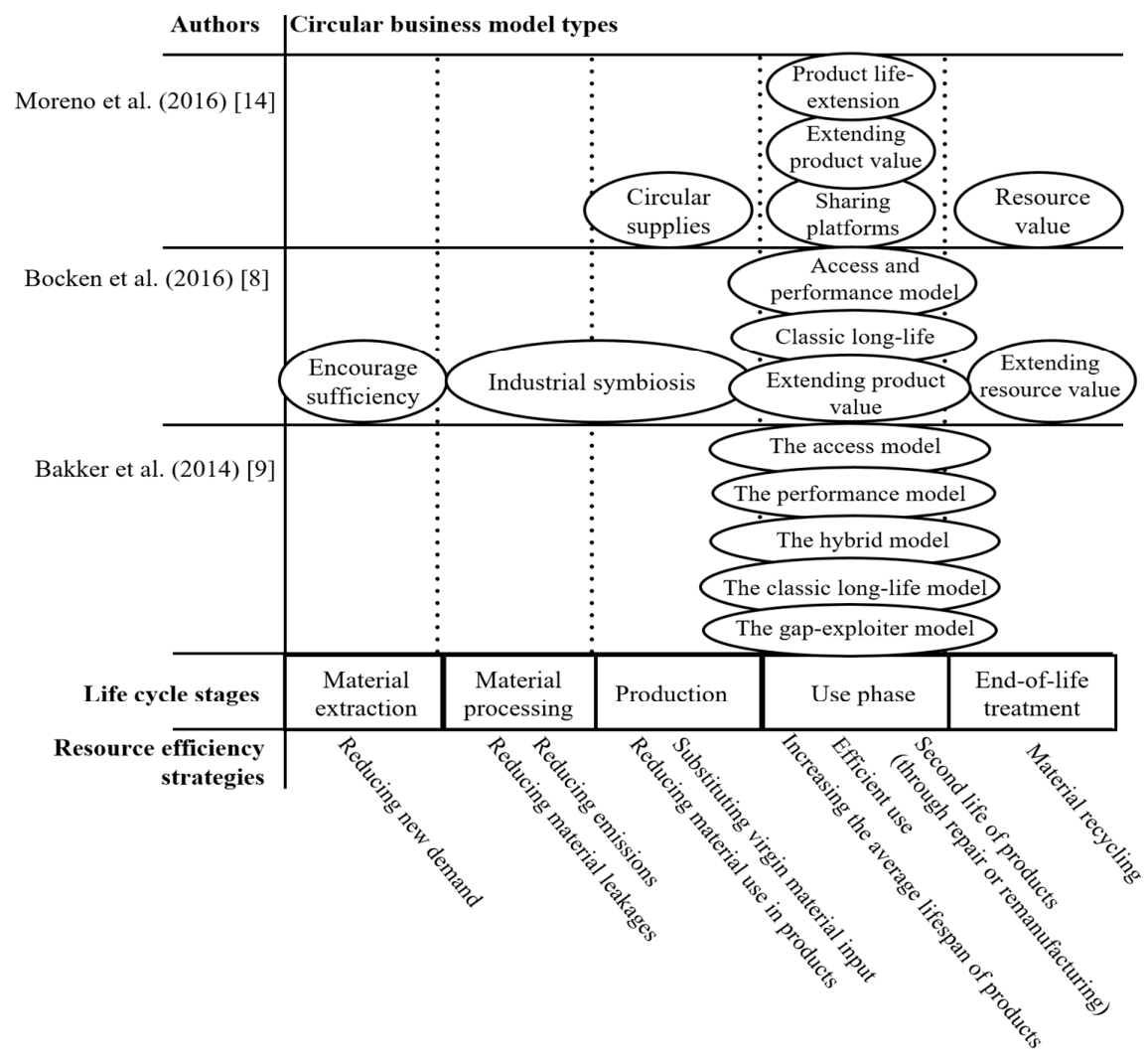

Figure 4. Typologies of circular business models from academic literature mapped against resource efficiency strategies.

Although Figure 4 reveals that authors' understanding of what a circular business model is remains heterogeneous, there appears to be agreement that circular business models lend themselves to:

- substituting primary material input with secondary production;

- extending the useful lifetime of products through design for longer average lifespans and enabling second life (e.g., repair or remanufacturing); and

- material recycling. 
There is still a lack of consensus as to whether production-related resource efficiency strategies (e.g., reducing material leakages and emission reduction) are included in circular business models. Moreover, Bocken et al. include reducing new demand for products as desirable [8], which other scholars do not explicitly include. Authors offer little explanation as to how the typologies were developed and whether the typologies are representative of business models in various industry sectors. Apart from Bakker et al. [9], authors do not seem to use consistent defining criteria in the various types of circular business models (e.g., a specific type of revenue flow as a defining criteria). Moreover, some of the types, e.g., Sharing Platforms or Industrial Symbiosis, raise the question if, besides their change in material flows, business model elements truly differ from the ones of linear business models. Therefore, it is worth examining how scholars in the field understand and distinguish between the circular and linear business model concepts and elements. This analysis is presented in the following section.

\subsection{How Are Circular Business Models Different to Linear Ones?}

The term "circular" implies that business models designed to support circular strategies and the associated changes in material flows are, to some degree, different from business models delivering offers that result in linear material flows. However, it is unclear if the generic business model elements of a circular business model are conceptually different from those in a linear business model. Clarifying potential differences between the concepts of linear and circular business models is important to determine whether studying circular business models requires novel tools and frameworks or if the ones used to examine linear business models remain valid.

Scholars commonly associate circular business models with characteristics such as increased collaboration' [14-16,18], 'pay for performance' instead of ownership [15,18,49,61], and operating 'reverse logistics' $[15,17,36,61,62]$. Although such specific configurations of the business model elements are assumed to become more common, given the variety in offers, product types, and resource efficiency strategies of business models that are claimed to be "circular", these characteristics are unlikely to be applicable across many companies [59]. Böckin et al. [63] offer a list of 13 generic product characteristics, such as a consumable product, low frequency use, and fashion driven. These product characteristics are assumed to influence which resource efficiency strategy has the highest reduction potential, but also influence the changes in business models that can support realising the resource efficiency strategy and change in material flow. Adjusting the business model is understood only as "a means to an end" [63] and, depending on product characteristics, different business model innovations are suitable. Therefore, instead of a certain configuration of business model elements, e.g., a PSS and shared-use model, the key difference of circular business model elements, compared to linear ones, appears to be the embeddedness of a circular strategy in the offer, which can alter material flows (see Section 3.3).

However, when a company's business model entails an offer that enables several use phases, and thereby several sequences of value generation, it will result in a more complex supply chain with several cycles $[10,53]$. In these cases, business model elements may take place repetitively, with different configurations in each cycle (e.g., different customer segments in each use phase). In such instances, the value proposition element may be regarded as more fluid and dynamic, as the value offered around a product may change through a product's life cycle [60,64]. More extensive research is needed to clarify whether these observations are true for a larger sample of circular business models.

While understanding of circular business models varies, several generic principles stemming from resource efficiency science determine whether implementing the embodied circular strategies will result in resource efficiency gains. The following section offers a review of the main considerations for achieving resource efficiency gains from circular strategies.

\section{Considerations for Implementing Circular Strategies}

The preceding analysis showed that scholars regard circular business models as business models that operate resource efficiency strategies, such as the substitution of primary material input with secondary 
production, extended useful life of products, and material recycling. These circular strategies are sometimes regarded as being synonymous with resource efficiency gains. However, implementing circular strategies does not by default lead to increased resource efficiency $[7,65]$. Therefore, the goal of resource efficiency has to be specifically set when implementing circular strategies. To aid the effective implementation of circular strategies in practice, three main contingencies that can impede resource efficiency gains from circular strategies are explored in the next sections.

\subsection{Replacement versus Reuse}

Reuse (e.g., through repair or remanufacturing) has long been promoted as an effective strategy to extend product lifetime and enhance resource efficiency. The main idea behind reuse is that it can substitute high impact primary production with lower impact secondary production [65]. Although this is generally true, reuse of products does not guarantee resource efficiency gains. The resource efficiency gains of reusing a product or part, for instance, depend on the processes needed to return a product to a suitable state or location, as well as on the use-phase impacts in a second life [65]. For products with high impact in the production phase and small impact in the use phase, life extension through reuse may indeed have the highest potential for resource efficiency gains $[6,66]$. For products with high use-phase impact, such as energy using products, life extension through reuse does not always have the highest potential for resource efficiency gains [65]. If energy savings from improved efficiency during use outweigh the embedded energy saving from avoiding primary production, replacement with more efficient products may be a preferable strategy $[6,7,65]$. For an informed decision, the optimal lifetime of products needs to be identified [7]. Determining factors for this include the use-phase efficiency of a reused product compared to its initial state, and the use-phase efficiency of a new product alternative [65]. However, as products are becoming more energy efficient, the relative importance of embodied impacts will become more significant, so the prominence of reuse as an abatement strategy is likely to increase in the future [65].

\subsection{Limits to Material Recycling}

If life extension and reuse is not a viable option, the waste hierarchy framework [67] suggests recycling as a strategy to closing the loop at lower value. The benefits of recycling are widely accepted, as the energy needed for recycling is generally substantially lower than the energy needed to produce the material from the ore [68]. However, there are inherent limits to the resource efficiency gains that can be achieved with recycling. Inefficiencies at each stage of the recycling process will always keep recycling efficiencies lower than 100\%. Moreover, liberating materials in complex product designs poses barriers to efficiency and causes material losses [68]. Depending on the material and circumstances such as location, electricity-generation mixes, collection system, and recycling processes, the resource efficiency gains from reducing primary material input may be outweighed by the resource efficiency gains associated with recycling processes (e.g., from reverse logistics or powering recycling equipment) [69]. For some bio-based materials, waste-to-energy conversion is, under certain conditions, the preferred strategy [70]. Generally, even if recycling strategies have the potential to reduce the total environmental burden, they may not be able to influence all different environmental parameters and impact categories [71]. Different situations share common characteristics, but each one is ultimately unique, and a careful analysis of the energy use and environmental impacts against the alternatives is required [69].

\subsection{Rebound Effects}

Although the discussed strategies for closing product and material loops have a strong potential for resource efficiency gains, Zink and Geyer [34] show that what happens at the end-of-life is relatively unimportant if it does not reduce primary production. If the resulting secondary production does not reduce primary production, implementing circular strategies risks increasing overall production, partially or fully offsetting their resource efficiency gains. Zink and Geyer [34] describe two 
mechanisms that can lead to such rebound effects: first, when secondary products are not compatible alternatives to primary products, and second, if they reduce prices and therefore lead to increased consumption. Suggested measures to avoid these rebound effects are to ensure that secondary products are good substitutes for primary ones, and that they target markets where consumers' price sensitivity is low [34]. The resulting market impacts of the end-of-life treatment are of critical importance, so displacing primary production should be at the core of circular strategies, rather than a narrow focus on closing resource loops [34]. However, this inherently causes the cannibalisation of sales, and Zink and Geyer [34] caution that circular strategies that can truly boost resource efficiency gains and reduce environmental impacts are of limited interest for manufacturers of products that can be cannibalised. Another form of rebound effect of circular strategies found is that strategies may lead to superior results at product level, but may trigger rebound effects at system level through more intensified use of products or services $[4,72,73]$.

\section{A Definition for Circular Business Models}

The preceding analysis revealed which resource efficiency strategies scholars deem relevant in the context of circular business models. The resource efficiency field is generally broader than the research on strategies enabling cycling of products, parts and materials to close resource loops. It should be noted that, depending on the circumstance, other resource efficiency strategies that do not cycle resources may have greater potential to improve resource efficiency. Therefore, the choice of resource efficiency strategy should be guided by life cycle assessment [31]. The analysis showed that authors regard resource efficiency strategies that enable substituting primary material input with secondary production, extending the useful life of products and parts, and closing material loops as the key strategies operationalised by circular business models (see Section 4). Based on this finding, a revised definition is suggested.

A circular business model is how a company creates, captures, and delivers value with the value creation logic designed to improve resource efficiency through contributing to extending useful life of products and parts (e.g., through long-life design, repair and remanufacturing) and closing material loops.

Extending the useful life and closing material loops includes the upstream value chain, substituting primary material input with secondary products, parts, and materials, as well as the downstream value chain, where products and parts are made available for additional use to utilise maximum embedded value. Ideally, both extending useful life of products and parts, and closing the material loop when the end-of-life of a product is irreversibly reached should be realised. This was found to be important, as previous definitions did not account for the fact that substituting primary materials or extending useful life does not necessarily result in closing the material loop at the end-of-life (see Section 3.1). The following section will offer a discussion of the analysis and the proposed definition.

\section{Final Remarks}

The concept of a circular business model is becoming prominent in advancing the transition towards a circular economy. However, despite its widespread usage, no common understanding of the concept exists. This creates a risk that the concept is used arbitrarily, and that important considerations to secure resource efficiency gains are insufficiently recognised.

This study contributes to filling the gap in three ways. Firstly, it clarifies the fundamentals of circular business models in management and resource efficiency literature and how these are interlinked. Essentially, business model innovation can help create an offer that embeds a circular strategy and successfully operates it. The other business model elements (Figure 3) can be configured in such a way that they help to overcome potential barriers to implementation, capitalise on the associated value flows (e.g., customer, environmental, and economic value), and align the business model to those of value chain partners to coordinate closing resource loops. Through which configurations of business model elements (e.g., a PSS and a Sharing Model) these changes are realised will vary with e.g., product and market characteristics. 
The paper's second contribution is in analysing how the concept of a circular business model is understood in recent academic literature and which of the resource efficiency strategies are often associated with it. The analysis revealed that there is not yet a coherent view about which resource efficiency strategies and changes in material flows classify a business model as "circular". The current understanding of authors diverges mostly in terms of production-related resource efficiency strategies such as reducing material leakages and emission reduction, but also efficient use of products (Figure 4). Common understandings relate to substituting primary material input with secondary production, extending average lifetime of products through long-life design and measures, such as repair or remanufacturing, and recycling materials.

Thirdly, to help improve understanding and effective implementation, three main contingencies that can impede potential resource efficiency gains from circular strategies were identified: (1) determinants for when replacement is preferable to life-extending measures; (2) the limits to closing material loops through recycling; and (3) potential rebound effects of resource efficiency gains at system level. The overall finding is that circular strategies do not by default lead to increased resource efficiency. Therefore, designing a circular business model should be guided by the assessment of the life cycle impacts of its offer, as well as consideration of potential rebound effects.

Based on the three-fold analysis, this paper offered a definition to form a starting point for more focused research, defining circular business models as how a company creates, captures, and delivers value with the value creation logic designed to improve resource efficiency through contributing to extending useful life of products and parts (e.g., through long-life design, repair and remanufacturing) and closing material loops. With the definition deriving from analysis of its fundamentals in the resource efficiency and business model field, it contributes to practice and future research in several ways.

Firstly, the definition clarifies which resource efficiency strategies can be deemed as relevant key strategies in the context of circular business models. Secondly, it considers that product and material loops are often only closed within a larger value chain network, and that companies' circular business models may be a contribution to a value chain network that enables a circular strategy through coordinated business model innovation. Thirdly, the definition adopts a critical stance, as it highlights that, independent of their value chain position, companies should strive to take responsibility for closing material loops when the end-of-life is irreversibly reached and ensure that a gain in resource efficiency is achieved.

Two thematic avenues can be outlined for future research. Firstly, the question arises whether the proposed definition of the concept is helpful in guiding circular business model development and whether the concept as envisioned by theory can be implemented. Secondly, in some cases of closing material loops, value chains of companies will not end with the product leaving the company. Instead, a company will manage several connected networks of value generation beyond a single life of product. In these cases, business model planning will need to span several steps in the product life cycle $[10,54]$, ultimately rendering business model configurations more complex. Linear business model frameworks and tools may be of limited value in such cases. Future research should clarify where existing tools are sufficient, and where new frameworks and tools are required, which lend themselves better to effectively embed circular strategies in business model development.

This study has helped to frame the emerging research field, but several open questions around the circular business model concept remain. What improvements in environmental impact should be realised for a company to have a viable claim that it runs a circular business model? It is important to note that implementing circular strategies, even if improvements in resource efficiency are achieved, do not by default reduce environmental impact [55,62]; for instance, if environmental improvements at product level are outweighed by rebound effects at system level. Moreover, how much should a company contribute to cycling resources and closing resource flows to have a viable claim that it runs a circular business model? For instance, a company may have a business model that offers services for reverse logistics, but does not operate a circular strategy itself. Regardless of these limitations, this study has made a first attempt to integrate the resource efficiency and business model perspectives 
in a definition, which hopefully will help advance the circular business model concept beyond rhetoric and harness its potential.

Acknowledgments: This research was supported by the Mistra REES (Resource Efficient and Effective Solutions) program, funded by Mistra (The Swedish Foundation for Strategic Environmental Research). I would like to thank Professor Oksana Mont and three anonymous reviewers for their constructive comments on this research.

Conflicts of Interest: The author declares no conflict of interest. The founding sponsors had no role in the design of the study; in the collection, analyses, or interpretation of data; in the writing of the manuscript, and in the decision to publish the results.

\section{References}

1. European Commission. Communication from the Commission to the European Parliament, the Council, the European Economic and Social Committee and the Committee of the Regions: Closing the Loop-An EU Action Plan for the Circular Economy; European Commission: Brussels, Belgium, 2015.

2. Ellen MacArthur Foundation. Towards the Circular Economy: Economic and Business Rationale for an Accelerated Transition; Ellen MacArthur Foundation: Cowes, UK, 2013.

3. Stahel, W. The utilization-focused service economy: Resource efficiency and product-life extension. In The Greening of Industrial Ecosystems; The National Academies Press: Washington, DC, USA, 1994; pp. 178-190.

4. Lifset, R.; Graedel, T.E. Industrial ecology: Goals and definitions. In A Handbook of Industrial Ecology; Edward Elgar Publishing: Cheltenham, UK, 2002; pp. 3-15.

5. Frosch, A.R.; Gallopoulos, N.E. Strategies for manufacturing. Sci. Am. 1989, 261, 144-152. [CrossRef]

6. Allwood, J.M.; Ashby, M.F.; Gutowski, T.G.; Worrell, E. Material efficiency: A white paper. Resour. Conserv. Recycl. 2011, 55, 362-381. [CrossRef]

7. Bakker, C.; Wang, F.; Huisman, J.; Den Hollander, M. Products that go round: Exploring product life extension through design. J. Clean. Prod. 2014, 69, 10-16. [CrossRef]

8. Bocken, N.; De Pauw, I.; Bakker, C.; Van der Grinten, B. Product design and business model strategies for a circular economy. J. Ind. Prod. Eng. 2016, 33, 308-320. [CrossRef]

9. Bakker, C.; Den Hollander, M.; Van Hinte, E.; Zljlstra, Y. Products That Last: Product Design for Circular Business Models; TU Delft Library: Delft, The Netherlands, 2014.

10. Velte, C.J.; Steinhilper, R. Complexity in a Circular Economy: A Need for Rethinking Complexity Management Strategies. In Proceedings of the World Congress on Engineering, London, UK, 29 June-1 July 2016.

11. Forum for the Future. Circular Business Models; Forum for the Future \& Unilever: London, UK, 2015.

12. Van Renswoude, K.T.W.; Joustra, D.J.A. Circular Business Models: Part 1: An introduction to IMSA's Circular Business Model Scan; IMSA Amsterdam: Amsterdam, The Netherlands, 2015.

13. Accenture Strategy. Innovative Business Models and Technologies to Create Value in a World without Limits to Growth; Accenture Strategy: London, UK, 2014; pp. 1-24.

14. Moreno, M.; De los Rios, C.; Rowe, Z.; Charnley, F. A Conceptual Framework for Circular Design. Sustainability 2016, 8, 937. [CrossRef]

15. Lewandowski, M. Designing the Business Models for Circular Economy-Towards the Conceptual Framework. Sustainability 2016, 8, 43. [CrossRef]

16. Antikainen, M.; Valkokari, K. Framework for sustainable circular business model innovation. Technol. Innov. Manag. Rev. 2016, 6, 5-12.

17. Linder, M.; Williander, M. Circular Business Model Innovation: Inherent Uncertainties. Bus. Strategy Environ. 2015, 26, 182-196. [CrossRef]

18. Planing, P. Business model innovation in a circular economy reasons for non-acceptance of circular business models. Open J. Bus. Model Innov. 2015, 1, 1-11.

19. Wirtz, B.W.; Pistoia, A.; Ullrich, S.; Göttel, V. Business models: Origin, development and future research perspectives. Long Range Plan. 2016, 49, 36-54. [CrossRef]

20. Clift, R.; Druckman, A. Introduction: The Industrial Ecology Paradigm. In Taking Stock of Industrial Ecology; Springer: Berlin, Germany, 2016.

21. Jesson, J.; Matheson, L.; Lacey, F.M. Doing Your Literature Review: Traditional and Systematic Techniques; Sage: Thousand Oaks, CA, USA, 2011. 
22. Geyer, R.; Jackson, T. Supply loops and their constraints: The industrial ecology of recycling and reuse. Calif. Manag. Rev. 2004, 46, 55-73. [CrossRef]

23. Stahel, W. The Service Economy: 'Wealth without resource consumption'? Philos.Trans. R. Soc. Lond. A Math. Phys. Eng. Sci. 1997, 355, 1309-1319. [CrossRef]

24. Stahel, W. Resource-miser business models. Int. J. Environ. Technol. Manag. 2007, 7, 483-495. [CrossRef]

25. Stahel, W. The Performance Economy; Palgrave Macmillan: London, UK, 2010; Volume 572.

26. Mont, O.K. Clarifying the concept of product-Service system. J. Clean. Prod. 2002, 10, 237-245. [CrossRef]

27. Jeswiet, J.; Hauschild, M. EcoDesign and future environmental impacts. Mater. Des. 2005, 26, 629-634. [CrossRef]

28. McDonough, W.; Braungart, M. Cradle to Cradle: Remaking the Way We Make Things; MacMillan: London, UK, 2010.

29. Sundin, E.; Björkman, M.; Jacobsson, N. Analysis of service selling and design for remanufacturing. In Proceedings of the IEEE International Symposium on Electronics and the Environment, San Francisco, CA, USA, 10 May 2000.

30. Sundin, E.; Lindahl, M. Rethinking product design for remanufacturing to facilitate integrated product service offerings. In Proceedings of the IEEE International Symposium on Electronics and the Environment, San Francisco, CA, USA, 19-22 May 2008.

31. Östlin, J.; Sundin, E.; Björkman, M. Importance of closed-loop supply chain relationships for product remanufacturing. Int. J. Prod. Econ. 2008, 115, 336-348. [CrossRef]

32. Mont, O.; Tukker, A. Product-Service Systems: Reviewing achievements and refining the research agenda. J. Clean. Prod. 2006, 14, 1451-1454. [CrossRef]

33. Willskytt, S.; Böckin, D.; André, H.; Söderman, M.L.; Tillman, A.-M. Framework for Analysing Resource-Efficient Solutions. In Proceedings of the EcoBalance 2016, Tokyo, Japan, 3-6 October 2016.

34. Zink, T.; Geyer, R. Circular economy rebound. J. Ind. Ecol. 2017. [CrossRef]

35. Braungart, M.; McDonough, W.; Bollinger, A. Cradle-to-cradle design: Creating healthy emissions-A strategy for eco-effective product and system design. J. Clean. Prod. 2007, 15, 1337-1348. [CrossRef]

36. Wells, P.; Seitz, M. Business models and closed-loop supply chains: A typology. Suppl. Chain Manag. Int. J. 2005, 10, 249-251. [CrossRef]

37. Magretta, J. Why Business Models Matter; Harvard Business School: Boston, MA, USA, 2002.

38. Richardson, J. The business model: An integrative framework for strategy execution. Strateg. Chang. 2008, 17, 133-144. [CrossRef]

39. Teece, D.J. Business models, business strategy and innovation. Long Range Plan. 2010, 43, 72-194. [CrossRef]

40. Osterwalder, A.; Pigneur, Y. Business Model Generation: A Handbook for Visionaries, Game Changers, and Challengers; John Wiley and Sons: Hoboken, NJ, USA, 2010; pp. 1-281.

41. Strategyzer. Canvases, Tools, and More. 2016. Available online: https://strategyzer.com/canvas (accessed on 15 September 2017).

42. Afuah, A. Business Model Innovation: Concepts, Analysis, and Cases; Routledge: Abingdon, UK, 2014; pp. 1-333.

43. Massa, L.; Tucci, C.L. Business Model Innovation. In The Oxford Handbook of Innovation Management; Dodgson, M., Gann, D.M., Phillips, N., Eds.; University of Oxford: Oxford, UK, 2014; p. 18.

44. Zott, C.; Amit, R. Business Model Design: An Activity System Perspective. Long Range Plan. 2010, 43, 216-226. [CrossRef]

45. Zott, C.; Amit, R. The Fit between Product Market Strategy and Business Model: Implications for Firm Performance. Strateg. Manag. J. 2008, 29, 1-26. [CrossRef]

46. Bocken, N.; Short, S.W.; Rana, P.; Evans, S. A literature and practice review to develop sustainable business model archetypes. J. Clean. Prod. 2014, 65, 42-56. [CrossRef]

47. Zott, C.; Amit, R.; Massa, L. The business model: Recent developments and future research. J. Manag. 2011, 37, 1019-1042.

48. Mont, O. Innovative approaches to optimising design and use of durable consumer goods. Int. J. Prod. Dev. 2008, 6, 227-250. [CrossRef]

49. Tukker, A. Product services for a resource-efficient and circular economy-A review. J. Clean. Prod. 2015, 97, 76-91. [CrossRef]

50. Diener, D.L.; Williander, M.; Tillman, A.-M. Product-Service-Systems for Heavy-Duty Vehicles-An Accessible Solution to Material Efficiency Improvements? Procedia CIRP 2015, 30, 269-274. [CrossRef] 
51. Mont, O.; Dalhammar, C.; Jacobsson, N. A new business model for baby prams based on leasing and product remanufacturing. J. Clean. Prod. 2006, 14, 509-1518. [CrossRef]

52. Gullstrand Edbring, E.; Lehner, M.; Mont, O. Exploring consumer attitudes to alternative models of consumption: Motivations and barriers. J. Clean. Prod. 2016, 123, 5-15. [CrossRef]

53. Nussholz, J. Circular Business Model Framework: Mapping value creation architectures along the product lifecycle. In Proceedings of the Product Lifetimes and the Environment, Delft, The Netherlands, 8-10 November 2017.

54. Fischer, S.; O’Brien, M.; Wilts, H.; Steger, S.; Schepelmann, P.; Jordan, N.D.; Rademacher, B. Waste prevention in a "leasing society". Int. J. Waste Resour. 2015, 5, 1-9.

55. Karvonen, I.; Jansson, K.; Tonteri, H.; Vatanen, S.; Uoti, M. Enhancing remanufacturing-studying networks and sustainability to support Finnish industry. J. Remanuf. 2015, 5, 1-16. [CrossRef]

56. Whalen, K.; Nussholz, J. Building Extended Value Chains: Lessons from Swedish ICT Repair and Resale 'Gap Exploiters' for Original Equipment Manufacturers. In Proceedings of the Electronics Goes Green, Berlin, Germany, 6-9 September 2016; pp. 1-9.

57. Whalen, K.; Milios, L.; Nussholz, J. Bridging the Gap: Barriers and potential for scaling repair and reuse practices in the Swedisch ICT sector. Resour. Conserv. Recycl. 2017, in press. [CrossRef]

58. Schenkel, M.; Caniëls, M.C.; Krikke, H.; Van der Laan, E. Understanding value creation in closed loop supply chains-Past findings and future directions. J. Manuf. Syst. 2015, 37, 729-745. [CrossRef]

59. Roos, G. Business model innovation to create and capture resource value in future circular material chains. Resources 2014, 3, 248-274. [CrossRef]

60. Den Hollander, M.; Bakker, C. Mind the Gap Exploiter: Circular Business Models for Product Lifetime Extension. In Proceedings of the Electronics Goes Green, Berlin, Germany, 6-9 September 2016; pp. 1-8.

61. Laubscher, M.; Marinelli, T. Integration of Circular Economy in Business. In Proceedings of the Going Green-CARE INNOVATION, Vienna, Austria, 17-20 November 2014.

62. Kissling, R.; Coughlan, D.; Fitzpatrick, C.; Boeni, H.; Luepschen, C.; Andrew, S.; Dickenson, J. Success factors and barriers in re-use of electrical and electronic equipment. Resour. Conserv. Recycl. 2013, 80, 21-31. [CrossRef]

63. Böckin, D.; Willskytt, S.; Tillman, A.-M.; Söderman, M.L. What makes solutions within the manufacturing industry resource efficient? In Proceedings of the EcoBalance, Tokyo, Japan, 3-6 October 2016.

64. Spring, M.; Araujo, L. Product biographies in servitization and the circular economy. Ind. Mark. Manag. 2016, 60, 126-137. [CrossRef]

65. Cooper, R.D.; Gutowski, T.G. The Environmental Impacts of Reuse: A Review. J. Ind. Ecol. 2017, $21,38-56$. [CrossRef]

66. Quariguasi Frota Neto, J.; Walther, G.; Bloemhof, J.A.E.E.; Van Nunen, J.A.E.E.; Spengler, T. From closed-loop to sustainable supply chains: The WEEE case. Int. J. Prod. Res. 2010, 48, 4463-4481. [CrossRef]

67. European Parliament. Directive 2008/98/EC of the European Parliament and of the Council of 19 November 2008 on Waste and Repealing Certain Directives (Text with EEA Relevance); European Parliament: Brussels, Belgium, 2008.

68. Worrell, E.; Reuter, M. Handbook of Recycling: State-of-the-Art for Practitioners, Analysts, and Scientists, 1st ed.; Elsevier: Amsterdam, The Netherlands, 2014.

69. Gaines, L. To Recycle, or not to Recycle, that is the Question: Insights from Life-Cycle Analysis. MRS Bull. 2012, 37, 333-338. [CrossRef]

70. Björklund, A.; Finnveden, G. Recycling revisited-Life cycle comparisons of global warming impact and total energy use of waste management strategies. Resour. Conserv. Recycl. 2005, 44, 309-317. [CrossRef]

71. Choi, B.C.; Shin, H.S.; Lee, S.Y.; Hur, T. Life cycle assessment of a personal computer and its effective recycling rate (7 pp). Int. J. Life Cycle Assess. 2006, 11, 122-128. [CrossRef]

72. Agrawal, V.V.; Ferguson, M.; Toktay, L.B.; Thomas, V.M. Is leasing greener than selling? Manag. Sci. 2012, 58, 523-533. [CrossRef]

73. Scheepens, A.; Vogtländer, J.; Brezet, J. Two life cycle assessment (LCA) based methods to analyse and design complex (regional) circular economy systems. Case: Making water tourism more sustainable. J. Clean. Prod. 2016, 114, 257-268. [CrossRef]

(C) 2017 by the author. Licensee MDPI, Basel, Switzerland. This article is an open access article distributed under the terms and conditions of the Creative Commons Attribution (CC BY) license (http:/ / creativecommons.org/licenses/by/4.0/). 